\title{
Increasing the Brand Awareness of Ambassador School Surabaya through A Website
}

\author{
Aprillia Adella Suyanto \\ English Department, Faculty of Letters, Petra Christian University, Siwalankerto 121-131, Surabaya 60236, \\ INDONESIA \\ E-mail: aprilliaadella@gmail.com
}

\begin{abstract}
Ambassador School is a Christian school established in 2011. This school offers 3 main programs which are Baby Class, Preschool, and Elementary. There are 2 schools that are similar to Ambassador School which are Bethany Christian School and CMC/SMI School because of 3 aspects: the location, price, service. The main problem of Ambassador School is related to low brand awareness, in which there are only a small number of people who know about this school and those who know are not able to explain what Ambassador School really is. The best solution of this problem is by increasing Ambassador School's brand awareness by highlighting its strengths and uniqueness through a website. As the main concern is to increase brand awareness, a website will be the best solution since it does not only tell what a company sells, but also tells other information in detail that other promotional tools may not be able to do the same. There are 4 highlighted USPs: academics, Christian values, character education, and independence education. Highlighting all of this school's strengths and uniqueness on a website will enable Ambassador School to not only increase the brand awareness, but also lead them to be seen as a more credible and professional school.
\end{abstract}

Keywords: Brand Awareness, Promotional Tool, Website, Unique Selling Point

\section{INTRODUCTION}

The company where I did my internship was at an education field, which was a school named Ambassador School. It is located on Rungkut Megah Raya, Jalan Raya Rungkut, Kedung Baruk, Surabaya. Ambassador School was established in 2011 under Duta Terang Bangsa institution. The story of Ambassador School began in 2010 when the owner, who is Ms. Fany Lianto, had a desire to provide employment opportunities for the Sunday school teachers of a church that she and her husband handled since most of the teachers did not have a job at that time. Besides the Sunday school teachers, she also wanted to make the children there grow up as a generation with a good character as the character of Christ. Therefore, in accordance with the Christian's great commission to become Christ-like, they decided to set a priority that making the children grow with the Christ-like character as the most important goal of Ambassador School.

Throughout my three-month internship program at Ambassador School, the main problem that I found is that they are facing a low brand awareness. Based on the survey that I conducted, there are only a small number of people who know about this school and those who know are not able to explain what Ambassador School really is. One of the main reasons that I have identified based on this problem is because they still lack a tool to introduce themselves and project their uniqueness well. People find it difficult to look for some information since the Ambassador School itself does not have a certain platform to help them in introducing their service and showing what makes them different from other schools. In this case, Ambassador School Surabaya only relies on using social media, which are Instagram and Facebook, to promote their service. Even so, all of these platforms are not effective to increase the brand awareness of this school because it does not contain any information or proofs that highlight its uniqueness.

Based on this problem, I decided to increase Ambassador School's brand awareness by highlighting its strengths and uniqueness through a website to make this school become more differentiable than other schools. As websites are very crucial for a business nowadays, I believe Ambassador School should have it so that they will be seen as a credible and professional school. As 
they accept more and more students every year, the parents or students themselves need to find a trusted platform to gain information, which in this case most of them will directly look for the website. Not only that, by the existence of a website, the brand awareness of Ambassador School can be increased among its customers and prospects because they can have a better understanding about who Ambassador School really is. By that, they can attract more customers as the website itself will be focused on its Unique Selling Point and strengths.

\section{THE PRINCIPLES USED IN MAKING THE SOLUTION}

In order to produce a good promotional tool, I need some guidelines or theories to support the process of making it. Therefore, all of the theories in this chapter have been chosen to help me more focus on the title itself, which are mainly related to brand awareness and website.

\subsection{Brand and Branding}

2.1.1 Description of Brand

2.1.2 Description of Branding

2.1.3 The Importance of Branding

2.1.4 Steps to Create a Strong Branding

2.2 Brand Awareness

2.2.1 Definition of Brand Awareness

2.2.2 The Importance of Brand Awareness

2.3 Website

2.3.1 Definition of a Website

2.3.2 The Importance of a Website

2.3.3 Types of Website Design and its Pros \& Cons

2.3.4 Key Design Elements for User Engagement

2.3.5 Basic Steps to Make a Website

2.4 School Website

2.4.1 Definition of School Website

2.4.2 The Importance of Having School Website

2.4.3 The Features of a Good School Website

2.5 Unique Selling Point (USP)

2.5.1 Definition of Unique Selling Point

2.5.2 The Importance of Unique Selling Point

2.5.3 Ways to Determine Unique Selling Point

\section{METHOD}

\section{Purposes of the Data Collection}

There are two purposes of collecting the data. First, the data is done to justify whether a website is the right solution for Ambassador School's problem. Besides, the data collection has a purpose to find out the USP to be put on the promotional tool. In this case, I asked several questions in order to reach the conclusion of USPs that I include on the website.

\section{Methods of the Data Collection}

There were two ways that I used to arrive at the solution. The first method was by distributing questionnaires to customers. Due to the COVID-19 pandemic situation, I was unable to do the survey offline. Therefore, I had to do the survey through Google Form. In order to be filled by the customers, I asked the headmaster, Ms. Olive, to share the survey to the parents. The questionnaire is divided into 4 parts. In the first section, it focuses on the background of how the customers know Ambassador School and why they finally decided to enroll their children there. The second section mainly talks about the 
Suyanto: Increasing the Brand Awareness of

Ambassador School Surabaya through a Website

respondents' opinion regarding the competitors to get more insight about other schools. The third section is about the progress regarding the academic, English, and Christian values, in which at that time I assumed these 3 factors are the Ambassador School's strengths. The last section is about the justification about the website and suggestion for Ambassador School.

Besides, the second method I used to collect the data was by interviewing the CEO, Ms. Ester, and the headmaster of the school, Ms. Olive. I used the interview method to find out the USP and to match it with the result of the customers survey so that I can get the right data to be put on the promotional tool. The interview was divided into two meetings. The first meeting was on September 15 with the CEO, and it was continued on September 18 with the headmaster. In order to collect some data, I asked several questions including the strengths of Ambassador School

\section{Respondents of the Data Collection}

For the first method, which is the customers survey, the respondents of the survey are the parents of the current active students. The reason I chose parents as my respondents was because they are the one who know and understand about Ambassador School since they use the service, so that their responses can be more trusted. The survey was distributed from September 3 until September 14, 2020 and it was filled by 54 respondents from all parents of Preschool until Elementary. Based on the respondents' information, it can be concluded that they come from middle to high class background. As seen on their current jobs, private employees took on the first place and it was followed by entrepreneur.

Besides the customers, the CEO and the headmaster of Ambassador School also became my respondents. Since both of them are the top two leaders of Ambassador School, I think they must be understood about the school well. Not only that, having them as my respondents is also important to give me more insights more about what should be put and what should not be put on the promotional tool.

\section{FINDINGS AND DISCUSSION}
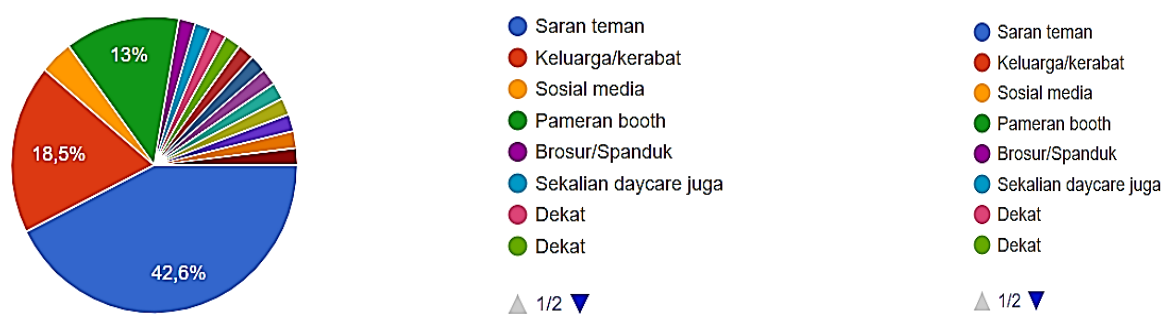

First of all, I asked the respondents of how they know about Ambassador School. Based on their answers, there are two highest answers. The highest answer is that they know Ambassador School from their friends' advice, and the second highest answer is 'family or acquaintance'. In this case, I found out that the way people know Ambassador School is mostly through a traditional way, which is through word of mouth. Thus, I conclude that it could be the reason why there are still a small number of people who know this school since they cannot promote themselves by using nowadays technology such as social media. 


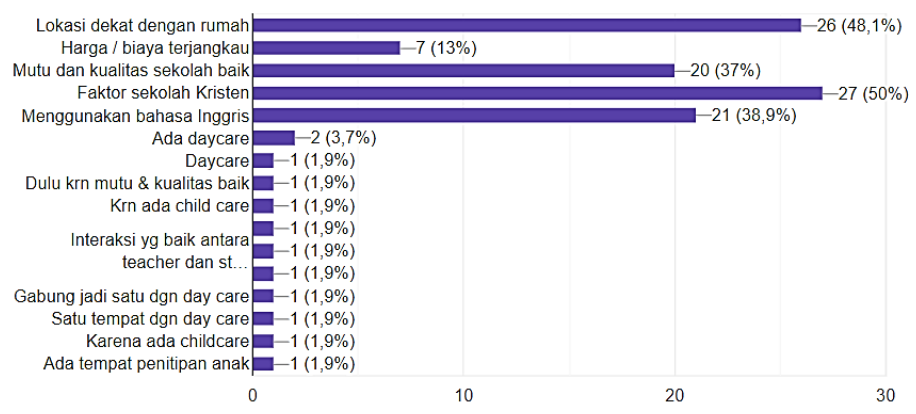

Then, I asked what makes the customers finally decided to enroll their children at Ambassador School. The 4 highest answers are because of the location, the background of a Christian school, the use of English, and the quality of the school. Based on this result, I conclude that the background of a Christian school and the use of English are quite promising to be considered by the parents to enroll their children there.

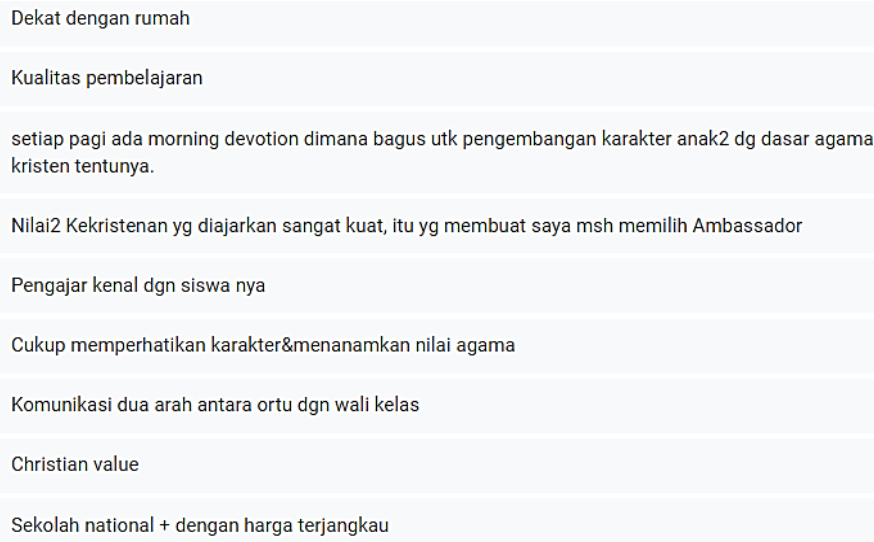

As the customers have known about how Ambassador School works, I asked them about the strengths that Ambassador School has. Based on this customer survey, there are 3 main things that are considered as Ambassador School's strengths. The first one is about the academic. For example, some respondents said that the curriculum used and the quality of the learning are great. The second thing is about Christian values, where Ambassador School never forgets to conduct spiritual activities, such as morning devotion and student chapel, to keep the students grow in faith. The last strength according to the respondents is about the character education. Therefore, these 3 things are approved by the customers as the strengths of Ambassador School.

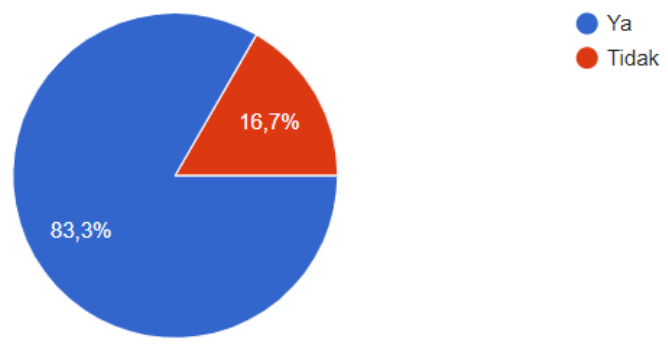

Last of all, I asked the respondents regarding the need of a website for Ambassador School to promote and introduce themselves. As a result, most of them answered that website is needed by Ambassador School. Therefore, I could arrive at the solution to highlight the uniqueness and strengths through a website. 
Suyanto: Increasing the Brand Awareness of

Ambassador School Surabaya through a Website

\section{Description of the Solution, its Rationale, and its Use}

The first thing is the type of the website. In this case, I decided to use the static website because of two reasons. First, since the focus of the website is promoting the school's profile and its uniqueness, static type will suit it the most because it does not need a regular update or complicated databases. Compared to the dynamic type that needs to be updated, it will be difficult for Ambassador School because this school itself does not have a certain person or department which is in charge or familiar with this thing. The second reason that I consider is because of its high-cost if it is using the dynamic ones. As the dynamic website charges more and excludes other expenses, it will waste the money which is not compatible with its needs.

Secondly, the domain name that is used for the website is www.ambassadorschool.sch.id. Since a domain name should reflect the products or services to be found easily by the customers. I decided to use a name that is similar to the school's name. Not only that, among the number of domain names, I decided to choose .sch.id. Since this domain name is specifically created for schools that are operating in Indonesia, I think it would be more appropriate to be used.

Thirdly, I put some key important contents that are divided into six parts:

\section{a. Home}

It will be the first part that will be seen by the viewers when they access the website. In this part, viewers are welcomed with the tagline and a brief introduction of who Ambassador School is. Not only that, I also put "Why Should you Choose Us?" box that will directly lead them to the USP part which is Learning Process, and three testimonials from representative parents. For the visualization, there are some pictures that the viewers can slide it including the building and other students' activities pictures. All of these contents in this part are made to attract them so that they can be interested in reading more.

\section{b. About Us}

This part is focusing on the background of the school and divided into 4 contents. The first content is 'History', where the information of how Ambassador School began is provided briefly here. The second content is 'Vision and Mission', where the school's vision and mission and its brief explanation are stated here. The third content is 'Core Values', where viewers can see what Ambassador School's values are. The last content I put is 'Learning Process', in which it emphasizes on Ambassador School's uniqueness. By putting the uniqueness on a special section, hopefully people can understand and realize that this school has strong uniqueness. Overall, all of these contents in this part are chosen with a purpose that the customers and people who are still not familiar with Ambassador School can know more deeply about it.

\section{c. Programs}

This menu explains about 3 programs offered by Ambassador School starting from Baby Class, Preschool (Kindergarten and Playgroup), and Elementary. In each program, there is information about the learning focus and schedule with a hope that customers or prospects can be more aware and have an overview of what each program looks like. For the visualization, I put 1-3 representative pictures that support the explanation and program itself.

\section{d. Facilities}

This menu mainly talks about the facilities provided by the school followed by the pictures as the visualization. The reason I put this menu is to show that the Ambassador School also provides good services in terms of facilities to support children's learning. There are 4 facilities that I highlight on the website which are Day-care, main hall, computer lab, and playground. Among all of these facilities, Day-care gets the most positive responses from the customers, so I include it on this menu. This service is well-accepted by parents that some of them think it is one of Ambassador School's 
strengths. Thus, I believe that it can attract the attention of parents, especially working parents, to use two services of Ambassador School at the same time, which are the school and Day-care itself.

\section{e. Gallery}

I put Gallery menu in order to give more evidences about how Ambassador School works. In this menu, I classify into 3 main activities of teachers and staff, students, and parents. First, for teachers and staff, there are two activities that I put which are teachers camp and teachers training. The reason I put a special section for teachers and include these activities is to convince viewers that Ambassador School cares about the teachers and trains them so they can give the best service for the customers. Second, for students, I categorize it into 2 sections which are indoor activity (teaching and learning process, big days, extracurricular, student chapel, and science fair), and outdoor activity (field trip and student camp). I believe this part can give an overview to parents of what activities that their children will do here. Last, I also put parents' activity, such as parents fellowship and parents class, to prove that Ambassador School does not only care about the children, but also cares with the parents.

\section{f. Contact}

The aim of this section is to make the visitors get the contact information of the school easily. When the visitors want to ask further questions or register their children, they can easily click on this part as there will be the contact information including address, phone number, and Email. Not only that, this menu can also be called as 'Call to Action'. As the previous menus mostly talk about who Ambassador School is and what they sell, the 'Contact' menu is placed on the last with a hope that viewers are interested and even trust their children at Ambassador School.

Thirdly, the languages that are used on the website are English and Indonesian. Since Ambassador School is a national plus school that conducts the lesson and communication in English, it is the plus point that should be highlighted and communicated through their website as well. In this case, I believe that the use of English language here will add value towards their customers' minds. Besides English, I also decided to use Indonesian language specifically for parents who do not speak English or are more comfortable with this language. In other words, the use of English is for image building while the use of Indonesian language is for the local parents' convenience.

Next, I put four important strengths that are highlighted on the website, specifically on the 'Learning Process' section. The first USP is about its academic. In this USP, there are 3 points that support it. First, Ambassador School uses modern curriculum, in which they combine national and international curriculum (Cambridge). Second, this school uses English as a medium of instruction. The reason that this USP should be included is because to convince parents that English is the main concern of Ambassador School for the sake of students' goodness in this era. The last support is how the teachers there are care about the students' academic progress. Some parents of the students said that they are satisfied with the way the teachers are care about the progress and the condition of their children. Therefore, I think that putting this strength can help Ambassador School to attract prospects more. The second USP is about Christian values. Based on the customers' answers, I can conclude that a Christian school is not only the label of this school, but they also apply it really well to the students. It can be seen based on how they conduct some spiritual activities to support students grow in faith such as morning devotion, student chapel, and student camp. The third USP is about character education. Based on the customers responses, they like the way how Ambassador School does not only educate the students academically, but also educates about character according to the basis of Christianity. The last USP is about independence education. According to the interview result and parent's testimonial, I found out that this aspect should be highlighted. As their vision is to prepare an excellent generation in all aspects, educating the students about being independent is also important.

Furthermore, the target of the viewers of the website will be more likely seen and visited by parents and everyone who has a possibility to use Ambassador School's service. Since the purpose of the website is to increase brand awareness, in which to make more people know and understand more about who Ambassador School really is, parents and prospects are the right target of it. Other than that, 
Suyanto: Increasing the Brand Awareness of

Ambassador School Surabaya through a Website

when they know more about Ambassador School, hopefully it can also lead them to enroll their children in this school as they are the one who will decide it.

\section{CONCLUSION}

In conclusion, since a lot of people still do not know about Ambassador School, I decided to highlight the uniqueness and strengths of Ambassador School Surabaya through a website to increase its brand awareness. Through a website, Ambassador School will be able to not only tell what they sell, but they can also introduce who they are clearly. Telling people about what a company sells to show their existence is not enough to increase the brand awareness, but people also need to know first who they are, what they do, and how they work. In this case, the best tool to do it all effectively is on a website. To get the right USPs, I conducted customers survey and interview with the CEO and headmaster. As a result, I got 4 USPs that I highlighted on the website. Besides making more people to be aware about this school, a website will benefit them to be seen as a more credible and professional school. The usage of this website will be more efficient and effective if the school place it on their social media and other promotional tools that they have. For example, they can put the URL on Instagram so that people can easily click it when they want to know more about Ambassador School.

\section{REFERENCES}

American Express. (2011). 5 Steps to Determine Your Unique Selling Point. Retrieved from https://www.americanexpress.com/en-us/business/trends-and-insights/articles/5-steps-to-determineyour-unique-selling-point/

Amanda. (2016). Why is Branding so Important for Your Business? [+ Real Life

Examples]. Retrieved from https://www.thebrandingjournal.com/2016/06/why-is-branding-importantbusiness/

Barraclough, D. (2020). What are the different types of websites? Retrieved from https://www.expertmarket.co.uk/web-design/different-types-of-websites

Brown, B.C. (2006). How to use the internet to advertise, promote, and market your business or web site - with little or no money. P.75. Retrieved from shorturl.at/ceiHI

Business Queensland. (2016). Creating a Website. Retrieved from https://www.business.qld.gov.au/starting-business/internet-start-ups/online-basics/creatingwebsites

Computer Hope. (2020). Website. Retrieved from https://www.computerhope.com/jargon/w/website.htm

Garett, R., Chiu, J., Zhang, Ly., Young, S. D. (2016). A Literature Review: Website Design and User Engagement. Retrieved from https://www.ncbi.nlm.nih.gov/pmc/articles/PMC4974011/

Malik, M. E., Ghafoor, M. M., Iqbal, H. K. (2013). Importance of Brand Awareness and Brand Loyalty in accessing Purchase Intentions of Consumer. 4(5), 168. Retrieved from https://ijbssnet.com/journals/Vol_4_No_5_May_2013/18.pdf

Optimizely. (2020). Unique Selling Point. Retrieved from https://www.optimizely.com/optimization-glossary/unique-selling-point/

Rouse, M. (2013). Unique Selling Point (USP). Retrieved from https://whatis.techtarget.com/definition/unique-selling-point-USP

Schul Homepage. (2020). Create a School Website - how to make a school website with pupils. Retrieved from https://www.schulhomepage.de/make-create-a-school-website/

School Webmasters (2018). What Makes the Best School Websites? Part 1 Retrieved from https://www.schoolwebmasters.com/Blog_Articles?entityid=375456

Sherman (2019). The Importance of a Website for Your Business Success. Retrieved from https://www.lyfemarketing.com/blog/importance-of-a-website/

Smithson, E. (2015). What Is Branding And Why Is It Important For Your Business? Retrieved from 
https://www.brandingmag.com/2015/10/14/what-is-branding-and-why-is-it-important-for-yourbusiness/

Savvidis, P. (2016). The Importance of Having a Good School Website. Retrieved from https://www.webanywhere.co.uk/blog/2016/04/importance-good-school-website/

Traster, J. (2018). 5 Steps to Building a Strong Brand. Retrieved from https://www.business2community.com/branding/5-steps-building-strong-brand-02001402

Walgrove, A. (2019). How to Increase Brand Awareness: Full Guide \& Strategy. Retrieved from https://blog.taboola.com/increase-brand-awarenesstoday/\#Why_is_Brand_Awareness_Important

Zesty.io. (2019). Dynamic vs. Static Websites: What's the Difference? Retrieved from https://www.zesty.io/mindshare/marketing-technology/dynamic-vs-static-websites/ 